\title{
Condyloma Acuminatum with Dysplasia
}

National Cancer Institute

\section{Source}

National Cancer Institute. Condyloma Acuminatum with Dysplasia. NCI Thesaurus. Code C97057.

Condyloma acuminatum that is associated with the presence of dysplastic epithelial changes. 